\title{
A Review of Clinical Trials in Emerging Botanical Interventions for Type 2 Diabetes Mellitus
}

\author{
Cheow Peng Ooi, Seng Cheong Loke and Tengku-Aizan Hamid \\ Institute of Gerontology, Universiti Putra Malaysia \\ Malaysia
}

\section{Introduction}

Although type 2 diabetes mellitus (T2DM) is pandemic globally, Asia-Pacific has the largest diabetes burden in the world (International Diabetes Federation, 2009). This region is home to more than half of the world's population with some of the richest and most developed countries alongside many developing as well as a significant number of poorest and least developed ones. Despite existing knowledge and recent progress in therapy, the majority of diabetic patients do not achieve an optimal blood glucose control. With a predisposition to disproportionate effect on the lower socioeconomic groups, the combination with the resulting poor health consequences, disability, and dependency is of concern (L.E. Egede, 2004). Taken together with the confluence of the recent upsurge of obesity and an ageing population, this will have far-reaching implications in terms of income security, social welfare and medical services (J.C. Chan et al., 2009; C. Pan et al., 2010). The consequent enormous health, social and economic burden will overwhelm the social and health care systems, particularly of the low and middle-income developing countries in the Asia-Pacific (D.O. Abegunde et al., 2007).

Controlling this disease is important for reducing complications, improving quality of life, and reducing the economic burden associated with disability and dependency (UKPDS 37, 1999). Strategies for the effective treatment of this devastating disease are of great interest to the general public, government organisations, and the healthcare industry. Besides nutritional intervention as an essential component of diabetes management, botanicals and associated products are also remedies for T2DM in traditional medicine practices. In the past decade, enhanced global research into botanicals has identified more than 600 plants as potential contributors to the management of T2DM (M. Modak et al., 2007; L.W. Qi et al., 2010).

Use of plant-based complementary and alternative medicine is common in many communities (H.Y. Chang et al., 2007; A. Metcalfe et al., 2010; H.T. Nguyen et al., 2010). In the past, the traditional 'observation' as remedies in complimentary alternative medicines, preliminary preclinical studies, and anecdotal evidence, have endorsed the use of these plants. However, their safety and efficacy in humans are of concern. Adding to the complexity of such issues are the challenges in the management of T2DM. Specifically, these are the use of pluralistic medical practices and the relevant roles of these botanicals in the 
management of T2DM in mainstream medicine (C.C. Shih et al., 2010). In addition, there are also issues of adequate regulatory standards and patients' disclosures to their mainstream medical practitioners (S. Tyreman, 2010). Thus, rigorous research in translating these botanicals to the clinical arena is warranted (M. Kantor, 2009).

There has been no evaluation of the clinical trials for the use of these emerging botanicals for type 2 diabetes mellitus. The aim of this review is to assess the effects of botanicals on type 2 diabetes mellitus. Existing opportunity for these botanicals in the management of diabetes and the state of the evidence for their anti-diabetic usefulness will be discussed. This includes issues pertaining to these clinical trials, the quality of antihyperglycemic efficacy data and related complementary metabolic effects. The adverse effects of interventions, a critical aspect of diabetic care, will also be emphasised. Finally, important limitations, which may affect the interpretation of data from these clinical studies and the implications for future research; in the context of T2DM in developing Asia-Pacific countries, will also be addressed.

\section{Research methodology}

\subsection{Methods}

Search was carried out in the following databases: MEDLINE, CINHAL, Proquest Health \& Medical Complete, ProQuest Dissertations \& Theses, CAM-PubMed, and the Cochrane Library Database from April 2006 to March 2011 using the MeSH terms CAM, alternative therapies, hypoglycemic plants or botanicals, anti-diabetic plants or botanicals and individual botanicals and supplement names from popular sources, each crossed with the term diabetes mellitus. Databases of ongoing trials (http://www.controlled-trials.com/ with links to several databases and https://www.clinicaltrialsregister.eu/) were also searched.

Only emerging botanical derived products or drugs not in the established armamentarium of modalities used in the current management of T2DM were included. Supplements in which animal products were major components were excluded. We also did not include soluble or dietary fibre supplements that were already established in conventional diabetes nutrition advice.

Specific filters for retrieving controlled clinical trial, double-blind, placebo-controlled, phase II, or III randomised controlled trials of any duration; published systematic reviews and meta-analyses of randomised controlled trials; and randomised controlled trials (RCT) in human adults (aged $\geq 18$ ), were incorporated. Hand searching was not performed, but reference lists of identified systematic reviews, meta-analyses, and pooled analyses were reviewed to identify further studies. Unpublished studies were also not sought. References in any articles that met the inclusion criteria were included. There were no language restrictions.

\subsubsection{Studies selection}

The results of the search from the various databases were entered in a bibliographic manager software, Endnote X4 (Thomson Reuters). Duplicates were automatically discarded. We screened the identified articles to ensure they met pre-determined inclusion criteria. To ensure uniformity of appraisal for each study a checklist of specified inclusion criteria was used. The initial review for all identified citations included titles or abstracts, or both. Following, a second review stage of full text publications for citations remaining after the first pass was carried out. We used a positive exclusion method to exclude only those 
publications that did not meet one or more of the inclusion criteria. In ambiguous cases, inclusion of studies was based on expert opinion.

\subsubsection{Data extraction}

A structured table was developed for data extraction to ensure uniformity of appraisal for each study as well as capturing all relevant data. Extracted data consisted of study characteristics (such as treatments and doses, status of T2DM and associated conditions, duration, and study location) and relevant outcomes (glycaemic control, adverse effects, morbidity, blood lipids level, body weight or body mass index).

\subsubsection{Outcome measures}

There were two primary outcomes: glycaemic control and adverse effects. These were considered as measures of efficacy and measures of tolerability respectively. Secondary outcomes were included when present. These included serum insulin, body weight or body mass index, blood lipids level and morbidity. Morbidity included both type 2 diabetes mellitus as well as cardiovascular-related comorbidity and all cause morbidity. The above data were only extracted and analysed when reported.

Data for glycaemic control, FBG and 2HPBG, was collected for trials of at least 6 weeks and over. For HbAic, trials over three months were considered. Data of all other outcomes will be collected from studies of any duration.

\subsubsection{Statistical analysis}

Analyses were performed on data that were explicitly reported in the individual papers, with no imputations for data that were not reported. When available, we analysed the intention-to-treat population; when this was not possible, we used data from the last observation carried forward. The analyses were conducted using RevMan 5.0 meta-analytic software (The Cochrane Collaboration, 2008).

\subsection{Results}

The search returned a total of 45 publications and abstracts (Figure 1). After review of titles and abstracts, we identified and included 22 relevant papers. All were clinical trials (1 clinical trial, 1 controlled clinical trial, and 20 randomised controlled trials) (Table 1). Six were excluded because duration of these studies were less than 6 weeks. Another was excluded because the primary outcome was not glycaemic control or adverse effects. Of the 15 remaining studies, all were randomised controlled trials. All the trials consisted of different plant-based interventions.

\subsubsection{Characteristics of included studies}

There were fifteen studies that met all the inclusion criteria. Table 1 shows the characteristics of the trials. The study participants for each trial range from 24 to 109. All studies included both genders. The participants were middle-age and older adults. Study length ranged from 12 weeks to 4 months.

Four papers provided information on different forms of cinnamon extracts (S.M. Blevins et al., 2007; P. Crawford, 2009; B. Mang et al., 2006; S. Suppapitiporn\& N. Kanpaksi, 2006). Two papers provided information on different forms of Silybum marianum preparations (H.F. Huseini et al., 2006; S.A. Hussain, 2007) and another two papers provided findings of 


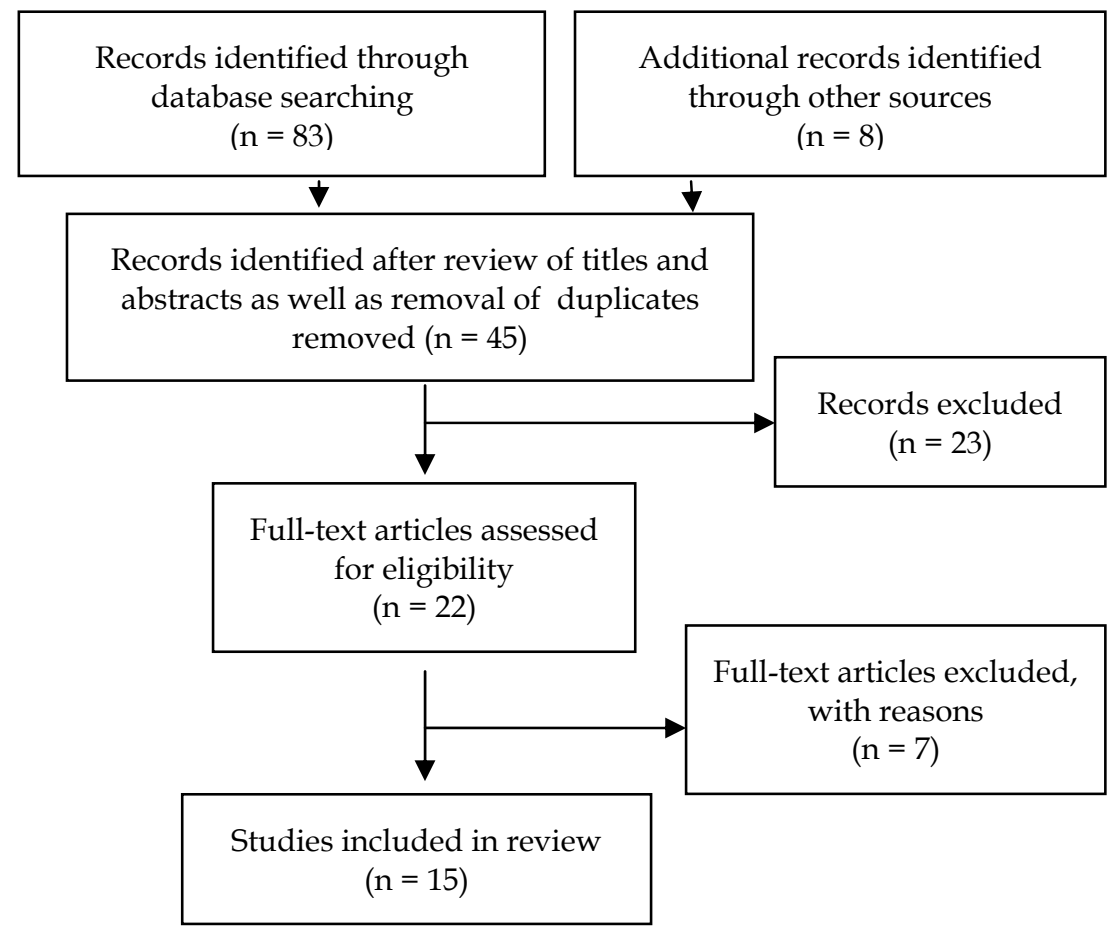

Fig. 1. Modified PRISMA (Preferred Reporting Items for Systematic Reviews and MetaAnalyses ) flow-chart of study selection (D. Moher et al., 2009)

catechin-containing tea preparations (T. Mackenzie et al., 2007; T. Nagao et al., 2009). The rest of the seven papers were focussed on 7 diffent plant-based preparations for T2DM (A.M. Dans et al., 2007; H.F. Huseini et al., 2009; V.T. Huyen et al., 2010; R. Kuriyan et al., 2008; F.R. Lu et al., 2008; V. Vuksan et al., 2008; S. Zibadi et al., 2008).

\subsubsection{Risks of bias}

Risk of bias assessments included assessments of minimisation of selection, performance, attrition, reporting biases as well as other sources of biases (A.R. Jadad et al., 1996; L.L. Kjaergard et al., 2001; K.F. Schulz et al., 1995).

One trial was a crossover randomised trial (V. Vuksan et al., 2008), while the rest was parallel-group design. Recruitment of patients was limited to the centres of the studies. Of the 15 included randomised trials, five trials described the methods of randomisation (P. Crawford, 2009; A.M. Dans et al., 2007; H.F. Huseini et al., 2006; T. Mackenzie et al., 2007; V. Vuksan et al., 2008). Among them, three used simple randomisation methods (random number generator, table and computer generated sequence) (A.M. Dans et al., 2007; T. Mackenzie et al., 2007; V. Vuksan et al., 2008), one used block randomisation technique (P. Crawford, 2009) and another used a balanced randomisation technique (H.F. Huseini et al., 2006). Only three trials reported generation of allocation concealment (P. Crawford, 2009; A.M. Dans et al., 2007; H.F. Huseini et al., 2006). The rest of the trials did not document adequate methods of randomisation. 


\begin{tabular}{|c|c|c|c|c|}
\hline Ref & Study design & Subjects & Intervention & Control \\
\hline $\begin{array}{l}\text { (S.M. Blevins et al., } \\
\text { 2007) }\end{array}$ & DBRPCT & 58 with T2DM & $\begin{array}{c}\text { Cinnamon } \\
\text { powder capsule } \\
\text { (C. cassia) }\end{array}$ & $\begin{array}{l}\text { Wheat flour } \\
\text { placebo capsule }\end{array}$ \\
\hline $\begin{array}{l}\text { (B. Mang et al., } \\
\text { 2006) }\end{array}$ & DBRPCT & 65 with T2DM & $\begin{array}{c}\text { Aqueous } \\
\text { cinnamon extract } \\
\text { (C. cassia) capsule }\end{array}$ & $\begin{array}{c}\text { Microcrystalline } \\
\text { cellulose placebo } \\
\text { capsule }\end{array}$ \\
\hline $\begin{array}{l}\text { (S. Suppapitiporn\& } \\
\text { N. Kanpaksi, 2006) }\end{array}$ & SBRPCT & 60 with T2DM & $\begin{array}{c}\text { Cinnamon } \\
\text { powder capsule } \\
\text { (C. Cassia) } \\
\end{array}$ & Placebo \\
\hline (P. Crawford, 2009) & RCT & 109 with T2DM & $\begin{array}{c}\text { Cinnamon } \\
\text { capsule (C. Cassia) }\end{array}$ & $\begin{array}{l}\text { No placebo } \\
\text { intervention }\end{array}$ \\
\hline $\begin{array}{l}\text { (A.M. Dans et al., } \\
\text { 2007) }\end{array}$ & DBRPCT & 40 with T2DM & \begin{tabular}{|c|}
$\begin{array}{c}\text { Momordica } \\
\text { charantia leaf } \\
\text { capsules }\end{array}$ \\
\end{tabular} & Placebo \\
\hline $\begin{array}{l}\text { (H.F. Huseini et al., } \\
\text { 2009) }\end{array}$ & DBRPCT & 50 with T2DM & $\begin{array}{c}\text { Citrullus. } \\
\text { colocynthis dried } \\
\text { fruit powder } \\
\text { capsules } \\
\end{array}$ & Placebo \\
\hline $\begin{array}{l}\text { (H.F. Huseini et al., } \\
\text { 2006) }\end{array}$ & DBRPCT & 51 with T2DM & $\begin{array}{c}\text { Silybum marianum } \\
\text { seed extract } \\
\text { tablets }\end{array}$ & Placebo \\
\hline $\begin{array}{l}\text { (S.A. Hussain, } \\
\text { 2007) }\end{array}$ & DBRPCT & 59 with T2DM & $\begin{array}{c}\text { Silybum marianum } \\
\text { extract tablets }\end{array}$ & Placebo \\
\hline $\begin{array}{c}\text { (V.T. Huyen et al., } \\
\text { 2010) }\end{array}$ & DBRPCT & 24 with T2DM & $\begin{array}{c}\text { Gynostemma } \\
\text { pentaphyllum tea }\end{array}$ & Placebo tea \\
\hline $\begin{array}{c}\text { (R. Kuriyan et al., } \\
\text { 2008) }\end{array}$ & DBRPCT & 60 with T2DM & $\begin{array}{l}\text { Coccinia cordifolia } \\
\text { leaves and fruit } \\
\text { extract capsules }\end{array}$ & $\begin{array}{l}\text { Maltosedextrin } \\
\text { capsule placebo }\end{array}$ \\
\hline $\begin{array}{l}\text { (F.R. Lu et al., } \\
\text { 2008) }\end{array}$ & $\mathrm{RCT}$ & 69 with T2DM & $\begin{array}{c}\text { Trigonella foenum- } \\
\text { graecum powder } \\
\text { capsules }\end{array}$ & $\begin{array}{c}\text { Chinese yam } \\
\text { powder placebo }\end{array}$ \\
\hline $\begin{array}{c}\text { (T. Mackenzie et } \\
\text { al., 2007) }\end{array}$ & DBRPCT & 49 with T2DM & $\begin{array}{c}\text { Green and black } \\
\text { tea extract } \\
\text { capsules }\end{array}$ & $\begin{array}{c}\text { Cellulose capsule } \\
\text { placebo }\end{array}$ \\
\hline $\begin{array}{c}\text { (T. Nagao et al., } \\
\text { 2009) }\end{array}$ & $\mathrm{RCT}$ & 43 with T2DM & \begin{tabular}{|c|} 
Green tea extract \\
(catechin-rich 528 \\
mg) beverage
\end{tabular} & \begin{tabular}{|c} 
Low dose \\
catechin $(96.3 \mathrm{mg})$ \\
placebo tea \\
\end{tabular} \\
\hline $\begin{array}{c}\text { (V. Vuksan et al., } \\
\text { 2008) }\end{array}$ & $\begin{array}{l}\text { DBRPCT, } \\
\text { crossover }\end{array}$ & 19 with T2DM & $\begin{array}{l}\text { Panax ginseng } \\
\text { extract capsules }\end{array}$ & $\begin{array}{c}\text { Vanilla flavoured } \\
\text { cornstarch } \\
\text { capsule placebo }\end{array}$ \\
\hline $\begin{array}{l}\text { (S. Zibadi et al., } \\
\text { 2008) }\end{array}$ & $\mathrm{RCT}$ & 48 with T2DM & $\begin{array}{l}\text { Pinus maritima } \\
\text { bark extract pill }\end{array}$ & Placebo \\
\hline
\end{tabular}

Table 1. Clinical trials of botanical interventions for type 2 diabetes mellitus. 
Blinding of all patients, trials investigators and assessors were reported in five trials (A.M. Dans et al., 2007; H.F. Huseini et al., 2009; H.F. Huseini et al., 2006; S.A. Hussain, 2007; T. Mackenzie et al., 2007). Eight trials did not report any aspects of blinding at all (V.T. Huyen et al., 2010; A. Khan et al., 2003; R. Kuriyan et al., 2008; F.R. Lu et al., 2008; B. Mang et al., 2006; T. Nagao et al., 2009; S. Suppapitiporn\& N. Kanpaksi, 2006; V. Vuksan et al., 2008). While the rest documented blinding of patients and trial investigators (S.M. Blevins et al., 2007) or assessors only (P. Crawford, 2009; S. Zibadi et al., 2008). Both dropouts of patients and intention-to-treat analysis were reported in five trials (S.M. Blevins et al., 2007; P. Crawford, 2009; A.M. Dans et al., 2007; F.R. Lu et al., 2008; S. Zibadi et al., 2008). One trial reported only dropouts of patients but not intention-to-treat analysis (H.F. Huseini et al., 2006).

Four papers did not mention appropriate inclusion, exclusion criteria or both (P. Crawford, 2009; R. Kuriyan et al., 2008; B. Mang et al., 2006; V. Vuksan et al., 2008). A statement of power calculation had been undertaken or give any justification for the numbers of participants needed to detect an effect of differences with intervention was documented in five papers (S.M. Blevins et al., 2007; P. Crawford, 2009; A.M. Dans et al., 2007; T. Mackenzie et al., 2007; V. Vuksan et al., 2008). Potential confounding factors were not elaborated in four papers (S.M. Blevins et al., 2007; P. Crawford, 2009; H.F. Huseini et al., 2009; B. Mang et al., 2006). There was also no uniform tool to assess adjunct dietary management in all these trials.

\subsubsection{Effects of interventions}

In view of the quality of data and variability of treatment, meta-analysis was not performed. One trial compared single botanical preparation without adjunct oral hypoglycaemics with placebo. The rest of the trials compared the botanical preparation with adjunct oral hypoglycaemicis with placebo. These tested botanicals included preparations of Cinnamon cassia, Momordica charantia, Citrullus Colocynthis, Silybum marianum, Gynostemma pentaphyllum, Coccinia cordifolia, trigonella foenum-graecum L, Camelia sinesis (tea) and Pinus maritima. Among them, Cinnamon cassia was tested in 4 trials, while Silybum marianum and Camelia sinesis (tea) were each tested in two trials. The reported outcomes included fasting blood glucose, postprandial blood glucose, HbA1c, fasting serum insulin levels, serum lipids level, symptoms, and adverse effects.

\section{Single botanical preparations versus placebo}

Compared with placebo (maltodextrin capsules), Coccinia cordifolia showed significantly better effect on normalisation of fasting blood glucose. There was a mean decrease of $15.6 \%$ in the intervention group compared to mean increase of $6 \%$ in the placebo group. Similarly, with the 2 hour postprandial blood glucose, there was a significant mean decrease of $18.5 \%$ in the intervention group. No significant change was noted in the placebo control group. There was also significant decrease in the glycosylated haemoglobin level in the intervention group.

Mild hypoglycaemic symptoms, perspiration, excessive hunger and slight dizziness, was noted post-prandially in 59\% of the participants in the intervention group. However, there was no significant difference in minor gastrointestinal adverse effects between the two groups. 


\section{Single botanical preparations with oral hypoglycaemic agent (OHA) adjuncts versus placebo}

The effect of Cinnamon cassia preparations and OHA in reducing fasting blood glucose level was not consistent. One trial showed a significant reduction in fasting blood glucose levels (B. Mang et al., 2006). However, two others reported no significant change with trials of 3 to 4 months (S.M. Blevins et al., 2007; S. Suppapitiporn\& N. Kanpaksi, 2006). There was no overall effect on HbA1c changes. Only one trial reported significant improvement in HbA1c level after 3 months (Standard mean difference (SMD) $0.12 \mathrm{~g} \%$; 95\% CI -0.26 to 0.50) (P. Crawford, 2009). However, this change did not translate into an overall significant effect size. Further, three trials of 3 and 4 month durations reported no significance improvement in the HbA1c with this botanical intervention (S.M. Blevins et al., 2007; B. Mang et al., 2006; S. Suppapitiporn\& N. Kanpaksi, 2006). Three trials of 3 and 4 months duration did not find any significant effect on the lipid levels (S.M. Blevins et al., 2007; B. Mang et al., 2006; S. Suppapitiporn\& N. Kanpaksi, 2006).

Adverse effect of hypersensitivity rash was reported in only one trial (P. Crawford, 2009). Comparison of these studies was difficult in view of different baseline biochemical characteristics (blood glucose, HbA1c, insulin, lipid level), weight, diet and concurent medications.

There was no significant difference between Camelia sinesis extracts (catechin and theaflavin) with OHA and placebo in HbA1c (T. Mackenzie et al., 2007; T. Nagao et al., 2009) and fasting blood glucose levels (T. Nagao et al., 2009). Although there was a significant increase in the insulin level in the catechin-rich beverage group, the number of participants was too small $(n=23)$ for further interpretation (T. Nagao et al., 2009). Adverse effects reported were profuse sweating and rash, which led to withdrawal from the study.

Compared with placebo, combination Silybum marianum and OHA significantly reduced both the FBG and HbA1c levels in two trials of four month durations (H.F. Huseini et al., 2006; S.A. Hussain, 2007). Even so, results of other parameters such as 2HPBG, BMI and lipid levels, were not consistent. No side-effects were reported.

Compared with placebo, the fruits and seeds capsules preparation of Momordica charantia and OHA showed no statistically significant effect on reduction of fasting blood glucose and HbA1c levels (A.M. Dans et al., 2007). Similarly, when compared with placebo, the treatment also showed no statistically significant reduction in secondary outcome measures, total cholesterol levels or body mass index when compared to placebo. However, the minor adverse effects of gastrointestinal discomfort led to discontinuation of treatment.

Ingestion of tea prepared from Gynostemma pentaphyllum and OHA for 12 weeks showed a significant reduction in FBG, $\mathrm{HbA1c}$ and insulin resistance, compared with placebo and OHA (V.T. Huyen et al., 2010). There were no adverse effects reported.

Intervention with Citrullus colocynthis and OHA in 25 patients for 2 months demonstrated significant reduction in both FBG and $\mathrm{HbA1c}$ levels, compared with patients taking placebo and OHA (H.F. Huseini et al., 2009). There were no significant changes in secondary outcome measures of lipid levels. However, three patients reported mild diarrhoea at the beginning of the study.

Patients on Trigonella foenum-graecum capsules and OHA for 12 weeks showed significant improvement glycaemic profile, FBG, $2 \mathrm{HPBG}$ and $\mathrm{HbA1c}$, as well as symptoms, compared with placebo (F.R. Lu et al., 2008). However, there were no significant secondary outcomes change of BMI, hepatic and renal functions. Adverse effects of abdominal discomforts and diarrhoea led to withdrawal from intervention. 
Compared with placebo, intervention with Panax ginseng extract capsules and OHA, significantly improved glucose tolerance and insulin sensitivity in a double-blind, placebocontrolled crossover randomised clinical trial (V. Vuksan et al., 2008). There were no significant changes in $\mathrm{HbA1c}$ as well as safety biochemical parameters of liver and kidneys. Adverse effects of hypoglycaemia was reported. In addition, there was a high number of dropouts $(50 \%)$. This was attributed to conflicting approaches used in the management of T2DM in mainstream medical practice and traditional herbal practice in the country of the trial.

Finally, Pinus maritima bark extract pill and OHA demonstrated significant reduction in FBG, HbA1c and LDL-cholesterol, compared with placebo and OHA (S. Zibadi et al., 2008). This was over a relatively short duration of 3 months. However, there was no documentation of adverse effects.

\subsection{Discussions}

\subsubsection{Summary of main results}

Fifteen randomised trials were included in this review. The exclusion of 7 trials was due to treatment duration of less than six weeks or reported outcomes not relevant to this review. The included trials compared different botanical preparation with or without combinations with hypoglycaemic agents versus placebo. Not all the trials provided data on dietary and lifestyle modification in patients with type 2 diabetes mellitus. Majority of the trials measured surrogate primary outcomes, some evaluated symptoms or adverse events. Two trials failed to demonstrate any improvements in the blood glucose control in terms of normalisation, reduction of fasting blood glucose, reduction of 2 HPBG responses and reduction of $\mathrm{HbA1c}$. This is in contrast with the majority that demonstrated improvements in the surrogate primary outcomes.

Only some trials examined secondary outcomes such as lipid levels or BMI. Safety biochemical parameters of the kidney and liver were examined in a limited number of trials. The low methodological quality and the general small sample size in these trials contributing to the low power of all the studies. Taken together with the limited number of the trials identified for individual botanical preparations, caution is needed in interpreting the findings of these trials. In all these studies, there were no statements on the healthrelated quality of life, well-being, socioeconomic status or costs.

Compared with placebo, six botanical preparations with oral hypoglycaemics, Cinnamon cassia, Citrullus Colocynthis, Silybum marianum, Gynostemma pentaphyllum, trigonella foenumgraecum $L$ and Pinus maritima seemed to have varying effects on blood glucose control. The hypoglycaemic agents used are sulphonylureas, metformin, thiazoledinediones, glinides, glitazones, acarbose or combination therapies. In addition to the conflicting findings of the four trials using preparations of Cinnamon cassia, the botanical preparations above with potential effects on glucose, warrant further trials.

\subsubsection{Applicability of evidence}

The fifteen trials available for this review were only a small fraction (less than $3 \%$ ) of the vast resources of potential botanicals for T2DM. For the four trials using Cinnamon cassia intervention, the extracts were of derived from different techniques, dosages and sources. Moreover, the placebos used as control of three of these trials also varied. One trial did not elaborate on the contents (S. Suppapitiporn\& N. Kanpaksi, 2006), while two others used 
wheat flour and microcrystalline cellulose (S.M. Blevins et al., 2007; B. Mang et al., 2006). Another trial did not use any placebo as control (P. Crawford, 2009). In addition, the time point for assessment of the effect of intervention for the four trials was not uniform. This time point was 3 months for two trials (S.M. Blevins et al., 2007; S. Suppapitiporn\& N. Kanpaksi, 2006)and 4 months for the other two(T. Mackenzie et al., 2007; B. Mang et al., 2006). Thus, these methodological issues may affect the results.

Even though there were two trials for each of the botanical, Camillia sinensis and Silybum marianum, different preparations were used. This means that none of the preparations of trials in this review were tested at least twice. Furthermore, many trials used the 'doubleblind'design but few reported blinding of outcome assessors. This may predisposed to the possibility of performance and reporting bias (D. Moher et al., 1998; K.F. Schulz et al., 1995).

\subsubsection{Quality of evidence}

Since all the trials in this review did not meet one or more essential risk of bias criteria, these trials were assessed having high risk of bias. There was no trial with moderate or low risk of bias. When quality criteria in terms of minimisation of selection, performance, attrition, and detection biases are met, trial of low risk of bias is indicated. Similarly, categorization into moderate risk of bias required the quality criteria to be partially fulfilled.

\subsubsection{Safety of botanical preparations}

The botanical preparations evaluated in this review generally did not report severe adverse effects. Thus, the conclusion on the safety of using these botanicals in the management of diabetic patients cannot be made. Further, many of the adverse effects were not sufficiently reported. None of the reviews looked for the effects of 'botanical-drug' interaction. It is important that both the beneficial and harmful effects in clinical trials of human given equal attention.

Previous reviews examined the use the different modalities of complementary and alternative medicine (R. Nahas\& M. Moher, 2009) or the use herbs and dietary supplements (G.Y. Yeh et al., 2003). This review differs in the respect that we are focussed on the update of the clinical trials of botanical preparations for type 2 diabetes mellitus of the last five years. This included randomised controlled clinical trials comparing botanical preparation with placebo or hypoglycaemic drugs in type 2 diabetes mellitus of duration exceeding six weeks. Previous reviews included both randomised and non-randomised controlled trials with interventions consisting of herbs, dietary supplements as well as minerals (vanadium and chromium) in both types of diabetics and healthy individuals. However, we limited our focus to potential botanicals for T2DM. Furthermore, our search strategy has no restriction to language. This is important as many of the trials with botanicals may appear in the languages in the regions where the use of botanicals is common, particularly in Asia. Finally, stringent criteria for quality assessment were used in this review based on recommendations by several authors (A.R. Jadad et al., 1996; L.L. Kjaergard et al., 2001; K.F. Schulz et al., 1995).

Current approaches to the use of botanical preparations differ with the type of medical practices. The expectation of mainstream medical practice is standardisation of extracts of botanicals extracts of predominantly specific parts of single plant (P. Talalay, 2001). This preparation is further investigated based on a set of criteria, which include preparation consistent with the description in the pharmacopoeia, chemical standardisation, biological assays, animal models, and clinical testing for the particular condition. In comparison, 
traditional medical practices may include non-herbal or herbal modalities or combination (H.T. Debas et al., 2006). The focus may be on symptoms, well-being and customising for each individual patient based on the differentiation of the patients' 'syndrome' based on the particular traditional medicine practice philosophy. However, in many communities in Asia, the use of plural practices for management of type 2 diabetes is common (K.L. Tackett\& M.C. Jones, 2009). Since there is evidence of the potential of botanicals contributing to management of T2DM, it is important to further understand their uses. The pleiotropic properties may have other benefits for these diabetics. Further insight may allow the use as possible expanding armamentarium of the glucose lowering therapeutic agents or complementing other aspects of treatment such as medical nutritional therapy. Improving the morale of the patients rather than creating conflict with the patient's use of other approaches, is important to ensure continuity of treatment and ultimately control of disease. In summary, the selected studies in this review showed variability of treatment interventions, control interventions and generally small effect sizes. None of the preparations were tested twice. As a result, there is insufficient evidence for any reliable conclusion of the potential benefits or harmful effects of these botanicals for type 2 diabetes mellitus.

\subsubsection{Limitations}

This systematic review has several limitations. First, there are limited trials available for selection. This may be due to the fact that research of these botanicals is still in the early days or publication bias. With the included trials, methodological issues were predominant. The poor quality of randomisation and blinding may exaggerate effects of the interventions due to systematic errors (bias). Potential bias may also occur during selection of patients, administration of treatment, and assessment of outcomes. Therefore, these methodologically less rigorous trials may show inappropriately skewed larger significant intervention effects than trials with more rigors (M. Egger et al., 2003; L.L. Kjaergard et al., 2001).

Small sample size of the trials leads to diminished power of the results. This may explain the absence of a statistically significant difference between botanical preparations used for interventions (E. Christensen, 2007; G. Piaggio\& A.P. Pinol, 2001). In other words, the analyses from the size of these trials may not establish with confidence that two interventions have equivalent effects.

All the selected trials reported end-of treatment responses, ranging from six weeks to four months. Important long-term responses beyond this period are not known. Finally, not all the trials provide information on ethnicity of the participants. The recruitment of patients was limited to the respective centre of study. In addition, all the preparations used in the intervention arms were tested only once, which made it impossible to pool data. Thus, the applicability of the results to other ethnic groups or populations is not known.

\section{Conclusion}

Some of the botanical preparations in this review may have beneficial effects on glycaemic glucose control in people with T2DM. However, at this point of time, we cannot recommend any for routine clinical use. All the trials had low methodological quality. The beneficial effects need to be confirmed by large rigorous randomised controlled trials of high-quality. In addition, the adverse effects also need to be further elucidated. Nevertheless, results from 
ongoing studies may provide more information on the potential clinical use of Cinnamon cassia, Momordica charantia and Camellia sinesis (Table 2).

\subsection{Implications for future research}

Although preclinical and early clinical trials suggest that the botanicals in this review may contribute to the management of T2DM, a potential methodological problem is the issue of the quality of these botanical preparations. An example is the varying effect of $C$. cassia preparations from different sources on glycaemic control. Some of the differences may arise with the varying climates, conditions for growing, harvesting and processing (U. Solimene et al., 2007). Different parts of the plant may have a different proportion of bioactive compounds present. This may add to the complexity of characterisation, production of reliable and consistently effective products. Therefore, there is a need to address the standardisation and the quality of the products used in clinic trials.

\begin{tabular}{|c|c|c|c|c|}
\hline Ref & Study design & Country & Intervention & Control \\
\hline (P. Crawford, 2011) & DBRCT & USA & $\begin{array}{c}\text { Cinnamon bark and } \\
\text { Cinnulin PF dietary } \\
\text { supplements }\end{array}$ & metformin \\
\hline (A. Tsiami, 2009) & DBRPCT & UK & Cinnamon capsules & $\begin{array}{c}\text { Starch capsule } \\
\text { placebo }\end{array}$ \\
\hline $\begin{array}{c}\text { (R. Ridout et al., } \\
\text { 2007) }\end{array}$ & DBRPCT & Canada & $\begin{array}{c}\text { Cinnamonforce } \\
\text { capsule }\end{array}$ & Placebo \\
\hline (K. Khawaja, 2009) & DBRPCT & Pakistan & $\begin{array}{c}\text { Momordica } \\
\text { charantia capsule }\end{array}$ & $\begin{array}{c}\text { Wheat flour } \\
\text { placebo capsule }\end{array}$ \\
\hline (C.H. Hsu, 2007) & DBRPCT & Taiwan & $\begin{array}{c}\text { epigallocatechin } \\
\text { gallate predominant } \\
\text { green tea extract }\end{array}$ & $\begin{array}{c}\text { Green tea extract } \\
\text { placebo }\end{array}$ \\
\hline
\end{tabular}

Table 2. Ongoing clinical trials of botanical interventions for type 2 diabetes mellitus.

The trials in this review did not examine the effect of the botanical interventions over a prolonged period (over 4 months). Thus, the effects on the micro and macro-complications well as other benefits in the patients with T2DM are not known. Moreover, with the different methodologies used, the presence of confounders, the varieties in the diet and the difficulty in recording dietary intake make it difficult to interpret the results. Furthermore, there is also the practicality of maintaining a 'stable' oral hypoglycaemic agents regime over a long period. Introduction of relevant clinically important outcome measures for long-term follow up may improve the quality of the trial.

Design of future trials comparing such botanical interventions with established hypoglycaemic drugs should be based on 'equivalence principle'. In view of the findings of preclinical studies suggesting benefits beyond glycaemic control, when comparing these botanical interventions combined with one or more established oral hypoglycaemic agents, verifying these potential benefits is suggested. Particularly, for the middle-aged and older patients with T2DM, relevant outcome measures should include functional outcomes, quality of life, well-being, socioeconomic status and costs. 
The quality of assessment of adverse events may be improved with a standardised format. Several components of selection bias that affect the quality of randomised controlled trials of this review required attention. This is the detailed reporting of the methods used to generate allocation sequence and allocation concealment. Adequate descriptions of withdrawal or drop-out during the trial and use of intention-to-treat analysis will also contribute to the quality of the trial.

\section{Acknowledgment}

The authors would like to acknowledge the kind support given by Institute of Gerontology, Universiti Putra Malaysia.

\section{Abbreviations}

MeSH, Medical Subject Headings; CAM, Complementary and Alternative Medicine; CCT, controlled clinical trial; DBRPCT, double-blind randomised placebo-controlled trial; DBRCT, double-blind randomised controlled trial; SBRPCT, single-blind randomised placebocontrolled trial; RCT, randomised controlled trial; T2DM, type 2 diabetes mellitus; UK, United Kingdom; USA, United States of America

\section{References}

Abegunde, D.O.; Mathers, C.D.; Adam, T.; Ortegon, M. \& Strong, K. (2007). The burden and costs of chronic diseases in low-income and middle-income countries. Lancet, Vol. 370, No. 9603 (Dec 8 2007), pp. 1929-38, ISSN 1474-547X (Electronic) 0140-6736 (Linking)

Blevins, S.M.; Leyva, M.J.; Brown, J.; Wright, J.; Scofield, R.H. \& Aston, C.E. (2007). Effect of cinnamon on glucose and lipid levels in non insulin-dependent type 2 diabetes. Diabetes Care, Vol. 30, No. 9 (Sep 2007), pp. 2236-7, ISSN 1935-5548 (Electronic) 0149-5992 (Linking)

Chan, J.C.; Malik, V.; Jia, W.; Kadowaki, T.; Yajnik, C.S.; Yoon, K.H. \& Hu, F.B. (2009). Diabetes in Asia: epidemiology, risk factors, and pathophysiology. JAMA, Vol. 301, No. 20 (May 27 2009), pp. 2129-40, ISSN 1538-3598 (Electronic) 0098-7484 (Linking)

Chang, H.Y.; Wallis, M. \& Tiralongo, E. (2007). Use of complementary and alternative medicine among people living with diabetes: literature review. J Adv Nurs, Vol. 58, No. 4 (May 2007), pp. 307-19, ISSN 0309-2402 (Print) 0309-2402 (Linking)

Christensen, E. (2007). Methodology of superiority vs. equivalence trials and non-inferiority trials. J Hepatol, Vol. 46, No. 5 (May 2007), pp. 947-54, ISSN 0168-8278 (Print) 01688278 (Linking)

Crawford, P. (2009). Effectiveness of cinnamon for lowering hemoglobin A1C in patients with type 2 diabetes: a randomized, controlled trial. J Am Board Fam Med, Vol. 22, No. 5 (Sep-Oct 2009), pp. 507-12, ISSN 1557-2625 (Print) 1557-2625 (Linking)

Crawford, P. (2011). Cinnamon Bark, Water-Soluble Cinnamon Extract, and Metformin as Initial Treatment for Type 2 Diabetes Mellitus: A Randomized, Controlled Trial, ClinicalTrials.gov identifier: NCT01302743 In: ClinicalTrials.gov, US National Institute of Health, Date of access: 12/04/2011, Available from: 
http:/ / clinicaltrials.gov/ct2/show/NCT01302743?term=cinnamon+diabetes\&rank $=1$.

Dans, A.M.; Villarruz, M.V.; Jimeno, C.A.; Javelosa, M.A.; Chua, J.; Bautista, R. \& Velez, G.G. (2007). The effect of Momordica charantia capsule preparation on glycemic control in type 2 diabetes mellitus needs further studies. J Clin Epidemiol, Vol. 60, No. 6 (Jun 2007), pp. 554-9, ISSN 0895-4356 (Print) 0895-4356 (Linking)

Debas, H.T.; Laxminarayan, R. \& Straus, S.E. (2006). Complementary and Alternative Medicine, Disease Control Priorities in Developing Countries. In: Jamison, D.T.; Breman, J.G.; Measham, A.R.; Alleyne, G.; Claeson, M.; Evans, D.B.; Jha, P.; Mills, A. \&Musgrove, P., pp. 1281-1291, The International Bank for Reconstruction and Development/The World Bank Group, ISSN Washington, D. C.

Egede, L.E. (2004). Diabetes, major depression, and functional disability among U.S. adults. Diabetes Care, Vol. 27, No. 2 (Feb 2004), pp. 421-8, ISSN 0149-5992 (Print) 0149-5992 (Linking)

Egger, M.; Juni, P.; Bartlett, C.; Holenstein, F. \& Sterne, J. (2003). How important are comprehensive literature searches and the assessment of trial quality in systematic reviews? Empirical study. Health Technol Assess, Vol. 7, No. 1 (February 2003), pp. 1-76, ISSN 1366-5278 (Print) 1366-5278 (Linking)

Hsu, C.H. (2007). Effect of Green Tea Extract on Type 2 Diabetes (GTT-DM), ClinicalTrials.gov Identifier: NCT00567905 In: ClinicalTrials.gov, US National Intitutes of Health, Date of access: 04/12/2011, Available from:

http://clinicaltrials.gov/ct2/show/NCT00567905?term=tea+diabetes\&rank=3.

Huseini, H.F.; Darvishzadeh, F.; Heshmat, R.; Jafariazar, Z.; Raza, M. \& Larijani, B. (2009). The clinical investigation of Citrullus colocynthis (L.) schrad fruit in treatment of Type II diabetic patients: a randomized, double blind, placebo-controlled clinical trial. Phytother Res, Vol. 23, No. 8 (Aug 2009), pp. 1186-9, ISSN 1099-1573 (Electronic) 0951-418X (Linking)

Huseini, H.F.; Larijani, B.; Heshmat, R.; Fakhrzadeh, H.; Radjabipour, B.; Toliat, T. \& Raza, M. (2006). The efficacy of Silybum marianum (L.) Gaertn. (silymarin) in the treatment of type II diabetes: a randomized, double-blind, placebo-controlled, clinical trial. Phytother Res, Vol. 20, No. 12 (Dec 2006), pp. 1036-9, ISSN 0951-418X (Print) 0951-418X (Linking)

Hussain, S.A. (2007). Silymarin as an adjunct to glibenclamide therapy improves long-term and postprandial glycemic control and body mass index in type 2 diabetes. J Med Food, Vol. 10, No. 3 (Sep 2007), pp. 543-7, ISSN 1096-620X (Print) 1096-620X (Linking)

Huyen, V.T.; Phan, D.V.; Thang, P.; Hoa, N.K. \& Ostenson, C.G. (2010). Antidiabetic effect of Gynostemma pentaphyllum tea in randomly assigned type 2 diabetic patients. Horm Metab Res, Vol. 42, No. 5 (May 2010), pp. 353-7, ISSN 1439-4286 (Electronic) 0018-5043 (Linking)

International Diabetes Federation. (2009). IDF Diabetes Atlas, (4th ), International Diabetes Federation, ISBN -13: 978-2-930229-71-3, Brussels, Belgium

Jadad, A.R.; Moore, R.A.; Carroll, D.; Jenkinson, C.; Reynolds, D.J.; Gavaghan, D.J. \& McQuay, H.J. (1996). Assessing the quality of reports of randomized clinical trials: is blinding necessary? Control Clin Trials, Vol. 17, No. 1 (Feb 1996), pp. 1-12, ISSN 0197-2456 (Print) 0197-2456 (Linking) 
Kantor, M. (2009). The role of rigorous scientific evaluation in the use and practice of complementary and alternative medicine. J Am Coll Radiol, Vol. 6, No. 4 (Apr 2009), pp. 254-62, ISSN 1558-349X (Electronic) 1546-1440 (Linking)

Khan, A.; Safdar, M.; Ali Khan, M.M.; Khattak, K.N. \& Anderson, R.A. (2003). Cinnamon improves glucose and lipids of people with type 2 diabetes. Diabetes Care, Vol. 26, No. 12 (Dec 2003), pp. 3215-8, ISSN 0149-5992 (Print) 0149-5992 (Linking)

Khawaja, K. (2009). Glycemic Response to Momordica Charantia in Type 2 Diabetes, ClinicalTrials.gov Identifier: NCT00823953. In: ClinicalTrials.gov, US National Institutes of Health Date of access: 04/12/2011, Available from: http:/ / clinicaltrials.gov/ct2/show/NCT00823953?term=Momordica+charantia+di abetes\&rank=1.

Kjaergard, L.L.; Villumsen, J. \& Gluud, C. (2001). Reported methodologic quality and discrepancies between large and small randomized trials in meta-analyses. Ann Intern Med, Vol. 135, No. 11 (Dec 4 2001), pp. 982-9, ISSN 0003-4819 (Print) 00034819 (Linking)

Kuriyan, R.; Rajendran, R.; Bantwal, G. \& Kurpad, A.V. (2008). Effect of supplementation of Coccinia cordifolia extract on newly detected diabetic patients. Diabetes Care, Vol. 31, No. 2 (Feb 2008), pp. 216-20, ISSN 1935-5548 (Electronic) 1935-5548 (Linking)

Lu, F.R.; Shen, L.; Qin, Y.; Gao, L.; Li, H. \& Dai, Y. (2008). Clinical observation on trigonella foenum-graecum $\mathrm{L}$. total saponins in combination with sulfonylureas in the treatment of type 2 diabetes mellitus. Chin J Integr Med, Vol. 14, No. 1 (Mar 2008), pp. 56-60, ISSN 1672-0415 (Print) 1672-0415 (Linking)

Mackenzie, T.; Leary, L. \& Brooks, W.B. (2007). The effect of an extract of green and black tea on glucose control in adults with type 2 diabetes mellitus: double-blind randomized study. Metabolism, Vol. 56, No. 10 (Oct 2007), pp. 1340-4, ISSN 00260495 (Print) 0026-0495 (Linking)

Mang, B.; Wolters, M.; Schmitt, B.; Kelb, K.; Lichtinghagen, R.; Stichtenoth, D.O. \& Hahn, A. (2006). Effects of a cinnamon extract on plasma glucose, $\mathrm{HbA}$, and serum lipids in diabetes mellitus type 2. Eur J Clin Invest, Vol. 36, No. 5 (May 2006), pp. 340-4, ISSN 0014-2972 (Print) 0014-2972 (Linking)

Metcalfe, A.; Williams, J.; McChesney, J.; Patten, S.B. \& Jette, N. (2010). Use of complementary and alternative medicine by those with a chronic disease and the general population--results of a national population based survey. BMC Complement Altern Med, Vol. 10, No. (Oct 2010), pp. 58, ISSN 1472-6882 (Electronic) 1472-6882 (Linking)

Modak, M.; Dixit, P.; Londhe, J.; Ghaskadbi, S. \& Paul, A.D.T. (2007). Indian herbs and herbal drugs used for the treatment of diabetes. J Clin Biochem Nutr, Vol. 40, No. 3 (May 2007), pp. 163-73, ISSN 0912-0009 (Print) 0912-0009 (Linking)

Moher, D.; Liberati, A.; Tetzlaff, J. \& Altman, D.G. (2009). Preferred reporting items for systematic reviews and meta-analyses: the PRISMA statement. PLoS Med, Vol. 6, No. 7 (Jul 2009), pp. e1000097, ISSN 1549-1676 (Electronic) 1549-1277 (Linking)

Moher, D.; Pham, B.; Jones, A.; Cook, D.J.; Jadad, A.R.; Moher, M.; Tugwell, P. \& Klassen, T.P. (1998). Does quality of reports of randomised trials affect estimates of intervention efficacy reported in meta-analyses? Lancet, Vol. 352, No. 9128 (Aug 22 1998), pp. 609-13, ISSN 0140-6736 (Print) 0140-6736 (Linking) 
Nagao, T.; Meguro, S.; Hase, T.; Otsuka, K.; Komikado, M.; Tokimitsu, I.; Yamamoto, T. \& Yamamoto, K. (2009). A catechin-rich beverage improves obesity and blood glucose control in patients with type 2 diabetes. Obesity (Silver Spring), Vol. 17, No. 2 (Feb 2009), pp. 310-7, ISSN 1930-7381 (Print) 1930-7381 (Linking)

Nahas, R. \& Moher, M. (2009). Complementary and alternative medicine for the treatment of type 2 diabetes. Can Fam Physician, Vol. 55, No. 6 (Jun 2009), pp. 591-6, ISSN 17155258 (Electronic) 0008-350X (Linking)

Nguyen, H.T.; Grzywacz, J.G.; Lang, W.; Walkup, M. \& Arcury, T.A. (2010). Effects of complementary therapy on health in a national U.S. sample of older adults. J Altern Complement Med, Vol. 16, No. 7 (Jul 2010), pp. 701-6, ISSN 1557-7708 (Electronic) 1075-5535 (Linking)

Pan, C.; Shang, S.; Kirch, W. \& Thoenes, M. (2010). Burden of diabetes in the adult Chinese population: A systematic literature review and future projections. Int J Gen Med, Vol. 3, No. (Aug 2010), pp. 173-9, ISSN 1178-7074 (Electronic) 1178-7074 (Linking)

Piaggio, G. \& Pinol, A.P. (2001). Use of the equivalence approach in reproductive health clinical trials. Stat Med, Vol. 20, No. 23 (Dec 2001), pp. 3571-7, ISSN 0277-6715 (Print) 0277-6715 (Linking)

Qi, L.W.; Liu, E.H.; Chu, C.; Peng, Y.B.; Cai, H.X. \& Li, P. (2010). Anti-diabetic agents from natural products--an update from 2004 to 2009. Curr Top Med Chem, Vol. 10, No. 4 (Feb 2010), pp. 434-57, ISSN 1873-4294 (Electronic) 1568-0266 (Linking)

Ridout, R.; Dugoua, J.; Koren, G. \& Einarson, T. (2007). The Anti-Diabetic and CholesterolLowering Effects of Cinnamon and Cassia Bark, ClinicalTrials.gov Identifier: NCT00479973. In: ClinicalTrials.gov, US National Institutes of Health Date of access: 04/12/2011, Available from:

http://clinicaltrials.gov/ct2/show/NCT00479973?term=cinnamon+diabetes\&rank $=6$.

Schulz, K.F.; Chalmers, I.; Hayes, R.J. \& Altman, D.G. (1995). Empirical evidence of bias. Dimensions of methodological quality associated with estimates of treatment effects in controlled trials. JAMA, Vol. 273, No. 5 (Feb 1995), pp. 408-12, ISSN 00987484 (Print) 0098-7484 (Linking)

Shih, C.C.; Su, Y.C.; Liao, C.C. \& Lin, J.G. (2010). Patterns of medical pluralism among adults: results from the 2001 National Health Interview Survey in Taiwan. BMC Health Serv Res, Vol. 10, No. (Jul 2010), pp. 191, ISSN 1472-6963 (Electronic) 14726963 (Linking)

Solimene, U.; Alkofahi, A.; Allemann, C.; Amigoni, M.; Aspan, R.; Azimova, S.; Bloodworth, B.C.; Caccialanza, G.; Caizzi, A.; Cheraghali, M.; Discalzi, A.; Eagles, P.; Fong, H.; Giachetti, D.; Goda, Y.; Harris, S.; Keller, K.; Law, R.; Ruichao, L.; Minelli, E.; Oh, M.; Rizzo, I.; Roll, D.B.; Serrano, S.; Scrabbi, L.; Sulaikah, M.; Tsang, R.; Guorong, W.; Wongsinkongman, P. \& Yusufu, H.U. (2007). WHO guidelines for assessing quality of herbal medicines with reference to contaminants and residues. WHO, Report 978924159444 8, Geneva.

Suppapitiporn, S. \& Kanpaksi, N. (2006). The effect of cinnamon cassia powder in type 2 diabetes mellitus. J Med Assoc Thai, Vol. 89 No. Suppl 3 (Sep 2006), pp. S200-5, ISSN 0125-2208 (Print) 0125-2208 (Linking) 
Tackett, K.L. \& Jones, M.C. (2009). Complementary and Alternative Medicines for the Treatment of Diabetes. Journal of Pharmacy Practice, Vol. 22, No. 6 (Dec 2009), pp. 546-552, ISSN 0897-1900 (Print) 1531-1937 (Linking)

Talalay, P. (2001). The importance of using scientific principles in the development of medicinal agents from plants. Acad Med, Vol. 76, No. 3 (Mar 2001), pp. 238-47, ISSN 1040-2446 (Print) 1040-2446 (Linking)

The Cochrane Collaboration. (2008). Review Manager (RevMan) 5.0, The Nordic Cochrane Centre, Copenhagen.

Tsiami, A. (2009). Is There a Metabolic Effect of Cinnamon on HbA1c, Blood Pressure and Serum Lipids in Type 2 Diabetes Mellitus? ClinicalTrials.gov Identifier: NCT00846898 In: ClinicalTrials.gov, US National Institutes of Health, Date of access: 04/12/2011, Available from:

http://clinicaltrials.gov/ct2/show/NCT00846898?term=cinnamon+diabetes\&rank=4.

Tyreman, S. (2010). Values in complementary and alternative medicine. Med Health Care Philos, Vol. 13, No. 4 (Nov 2010), pp. Online First ${ }^{\mathrm{TM}}, 23$ November 2010, ISSN 15728633 (Electronic) 1386-7423 (Linking)

UKPDS 37. (1999). Quality of life in type 2 diabetic patients is affected by complications but not by intensive policies to improve blood glucose or blood pressure control (UKPDS 37). U.K. Prospective Diabetes Study Group. Diabetes Care, Vol. 22, No. 7 (Jul 1999), pp. 1125-36, ISSN 0149-5992 (Print) 0149-5992 (Linking)

Vuksan, V.; Sung, M.K.; Sievenpiper, J.L.; Stavro, P.M.; Jenkins, A.L.; Di Buono, M.; Lee, K.S.; Leiter, L.A.; Nam, K.Y.; Arnason, J.T.; Choi, M. \& Naeem, A. (2008). Korean red ginseng (Panax ginseng) improves glucose and insulin regulation in wellcontrolled, type 2 diabetes: results of a randomized, double-blind, placebocontrolled study of efficacy and safety. Nutrition Metabolism $\mathcal{E}$ Cardiovascular Diseases, Vol. 18, No. 1 (Jan 2008), pp. 46-56, ISSN

Yeh, G.Y.; Eisenberg, D.M.; Kaptchuk, T.J. \& Phillips, R.S. (2003). Systematic review of herbs and dietary supplements for glycemic control in diabetes. Diabetes Care, Vol. 26, No. 4 (Apr 2003), pp. 1277-94, ISSN 0149-5992 (Print) 0149-5992 (Linking)

Zibadi, S.; Rohdewald, P.J.; Park, D. \& Watson, R.R. (2008). Reduction of cardiovascular risk factors in subjects with type 2 diabetes by Pycnogenol supplementation. Nutr Res, Vol. 28, No. 5 (May 2008), pp. 315-20, ISSN 1879-0739 (Electronic) 0271-5317 (Linking) 


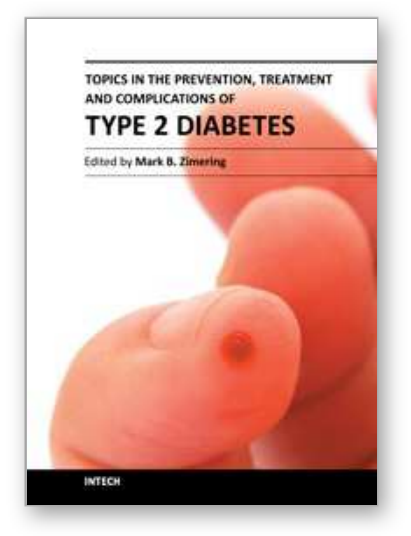

\author{
Topics in the Prevention, Treatment and Complications of Type 2 \\ Diabetes \\ Edited by Prof. Mark Zimering
}

ISBN 978-953-307-590-7

Hard cover, 340 pages

Publisher InTech

Published online 04, November, 2011

Published in print edition November, 2011

Type 2 diabetes is estimated to affect 120 million people worldwide- and according to projections from the World Health Organization this number is expected to double over the next two decades. Novel, cost-effective strategies are needed to reverse the global epidemic of obesity which is driving the increased occurrence of type 2 diabetes and to less the burden of diabetic vascular complications. In the current volume, Topics in the Prevention, Treatment and Complications of Type 2 Diabetes, experts in biology and medicine from four different continents contribute important information and cutting-edge scientific knowledge on a variety of topics relevant to the management and prevention of diabetes and related illnesses.

\title{
How to reference
}

In order to correctly reference this scholarly work, feel free to copy and paste the following:

Cheow Peng Ooi, Seng Cheong Loke and Tengku-Aizan Hamid (2011). A Review of Clinical Trials in Emerging Botanical Interventions for Type 2 Diabetes Mellitus, Topics in the Prevention, Treatment and Complications of Type 2 Diabetes, Prof. Mark Zimering (Ed.), ISBN: 978-953-307-590-7, InTech, Available from:

http://www.intechopen.com/books/topics-in-the-prevention-treatment-and-complications-of-type-2-diabetes/areview-of-clinical-trials-in-emerging-botanical-interventions-for-type-2-diabetes-mellitus

\section{INTECH}

open science | open minds

\section{InTech Europe}

University Campus STeP Ri

Slavka Krautzeka 83/A

51000 Rijeka, Croatia

Phone: +385 (51) 770447

Fax: +385 (51) 686166

www.intechopen.com

\section{InTech China}

Unit 405, Office Block, Hotel Equatorial Shanghai

No.65, Yan An Road (West), Shanghai, 200040, China

中国上海市延安西路65号上海国际贵都大饭店办公楼 405 单元

Phone: +86-21-62489820

Fax: $+86-21-62489821$ 
(C) 2011 The Author(s). Licensee IntechOpen. This is an open access article distributed under the terms of the Creative Commons Attribution 3.0 License, which permits unrestricted use, distribution, and reproduction in any medium, provided the original work is properly cited. 